\title{
O POETA E A FLORESTA: UM DIÁlOGO ENTRE DIREITO E LITERATURA PARA A CONSERVAÇÃO DA MATA ATLÂNTICA
}

LUCIANO JOSÉ ALVARENGA Professor do Centro de Atualização em Direito e Universidade Gama Filho, Brasil ljalvarenga@gmail.com

\section{Acórdão}

Agravo de Instrumento $\mathrm{n}^{\mathrm{o}}$ 1.0016.10.009466-9/001

Comarca: Alfenas

Relator: Desembargador Peixoto Henriques

Agravante: Ministério Público do Estado de Minas Gerais

Agravados: Mário de Oliveira Terra e outros

EMENTA: AGRAVO DE INSTRUMENTO. AÇÃO CIVIL PÚBLICA. AVERBAÇÃO DE RESERVA LEGAL. TUTELA ANTECIPADA. RECURSO PROVIDO. I) A "reserva legal" se destina à harmoniosa integração e efetiva concreção das determinações constitucionais consagradas nos arts. $5^{\circ}$ - XXIII, 170 - II e III, 182 - $2^{\circ}, 185$ - p. único, 186 - I e II e 225. II) Diante da desordenada devastação de nossas matas e da deplorável extinção de nossos bichos, intolerável coonestar iniciativas que, sob concepção exclusivamente individualista, ignoram o dever constitucional de cada um e, concomitantemente, de todos nós para com a manutenção do equilíbrio ecológico, respeitando manancial de elementos essenciais à vida humana. III) Independente de haver ou não área de floresta em propriedade rural, é obrigação do proprietário ou possuidor de imóvel rural 
adotar providências necessárias à restauração ou recuperação das formas de vegetação nativa, se adequando aos limites previstos no art. 16 do Código Florestal. (AI n ${ }^{\circ}$ 1.0016.09.100358-8/001, $8^{\mathrm{a}}$ CCív/ TJMG, rel. Des. Vieira de Brito, DJ 01-07-2010).

\section{ACÓRDÃO:}

Vistos etc., acorda, em Turma, a $7^{\text {a }}$ Câmara Cível do Tribunal de Justiça do Estado de Minas Gerais, sob a Presidência do Desembargador Wander Marotta, incorporando neste o relatório de fls., na conformidade da ata dos julgamentos e das notas taquigráficas, à unanimidade de votos, em dar provimento.

Data do Julgamento: 15 de fevereiro de 2011.

\section{Comentário}

Conta-se que Direito e Retórica "se imbricam desde a nascença, tendo esta surgido da necessidade de persuasão dos juízes num caso judicial sobre propriedade de terras, no mundo clássico". (BARTHES apud CUNHA, 2007, p. 1). Na contemporaneidade, o reconhecimento da proximidade epistemológica entre Direito e Literatura tem vindo a entusiasmar, no campo acadêmico, uma fecunda linha de pesquisa interdisciplinar e, na prática, análises e decisões que contribuem para resgatar a dimensão cultural do Direito, esquecida ou recalcada em tempos de predomínio do paradigma positivista. (OST, 2004, p. 58).

Um exemplo de diálogo entre esses dois campos do saber ocorreu no julgamento do Agravo de Instrumento 0537249-42.2010.8.13.0000, pela Sétima Câmara Cível do Tribunal de Justiça do Estado de Minas Gerais (TJMG). Depois de referir os argumentos jurídicos de seu voto, atinente à questão de averbação e conservação da reserva legal florestal, o relator, Desembargador Peixoto Henriques, evocou a poesia de Carlos Drummond de Andrade para, nas palavras do magistrado, "dela extrair soberba lição e, notadamente, vital exortação". (MINAS GERAIS, 2011). No pronunciamento jurisdicional, fez-se transcrição parcial de um conjunto de poemas (ou um vasto poema único) que o escritor mineiro dedicou à Mata 
Atlântica (ANDRADE; MAGNANINI; MARIGO, 1984; ANDRADE, 1997), região que outrora se estendia do Rio Grande do Norte ao Rio Grande do Sul, mas que sofreu um intenso processo de devastação desde o início da ocupação colonial, conforme representam as Figuras 1 e 2 .

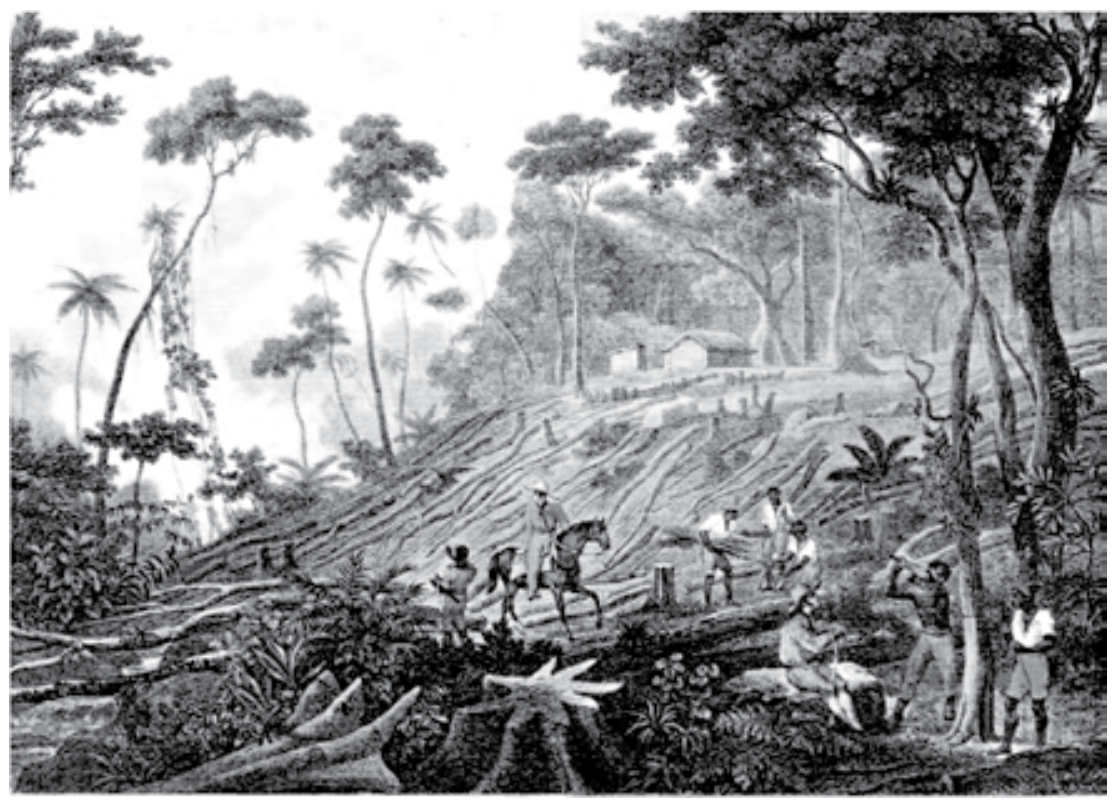

Figura 1: Defrichement d'une Foret - Desmatamento de uma floresta (Mata Atlântica). Pintura de Johann Moritz Rugendas (Fonte: Wikipedia). 


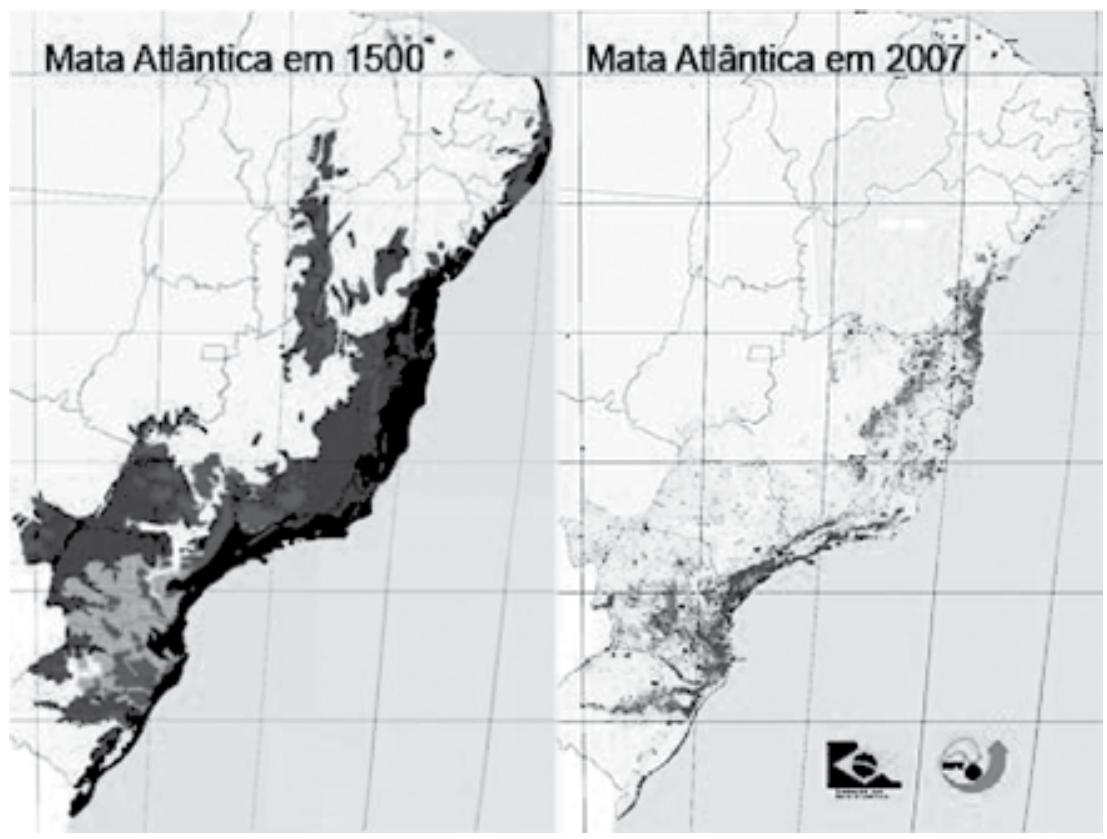

Figura 2: Representação do desflorestamento no bioma Mata Atlântica no intervalo 1500-2007 (Fonte: Fundação SOS Mata Atlântica e Instituto Nacional de Pesquisas Espaciais).

Transcrevem-se a seguir passagens do texto de Drummond (1984; 1997), que se colocam como uma crítica em relação ao modo de ocupação e aproveitamento dos sistemas naturais do Brasil e como uma exortação em defesa da vida:

Sem o lirismo das orquídeas,

Sem o charme decorativo das samambaias,

Nua de líquens e bromélias do litoral,

A mata de Caratinga, protegida dos ventos,

Espera de nós

A proteção maior contra o machado,

A serra mecânica, o fogo.

De cada cem árvores antigas

Restam cinco testemunhas acusando

O inflexível carrasco secular. 
Restam cinco, não mais. Resta o fantasma Da orgulhosa floresta primitiva.<smiles>[AlH2]</smiles>

Jacupemba, perseguida jacupemba, De tua sorte quem se lembra, quem se lembra?

O cantor-risada

Do japuguaçu

No alto da embaúba

Me deixa intrigado.

Ele ri de Quê?

Da mão que derruba

Seu ninho cuidado?

Vou adivinhar:

Se a ave ri, coitada, É que, por destino, Não sabe chorar.

Penúltima jacutinga do Brasil?

Ou última, talvez?

Sem coco de palmito-juçara para comer, Sem galho forte para o pouso, Sem ambiente para viver,

A jacutinga espera o fim de toda a fauna.

Sou pintor ou pintura?

As cores arcoirisam no meu manto.

Objeto luxuoso, esvoaçante

Gravura colorida,

Não me neguem, por Deus, direito à vida.

Um som de flauta se derrama

No que restou da terra comburida.

O sanhaço é nostálgica lembrança

De outro tempo, outra mata, noutra vida.

Meu verdoengo tucano

De bico leve e guloso,

Escuta este teu amigo:

Te arriscas, se não me engano, 
A ter um fim doloroso

Se não te pões ao abrigo

Do destruidor ser humano.

Olha o barbado, olha o bando do barbado!

Olha o coro de Barbados na floresta!

À sua maneira,

Está berrando, aos deuses implorando

Que detenham a fúria arrasadora

Da sacrificada mata brasileira.

$[\ldots]$

Riacho Campo Belo,

Crivado de pedras lisas,

Como rápido deslizas

Modulando um ritornelo:

'Mais amar sabe quem ama

Sua terra e sua dama.'

Vem, Esperança, e pousa leve,

Como um traço de verde giz

(É meu anseio que te escreve)

Sobre a sorte do meu país.

A água serpeia entre musgos seculares.

Leva um recado de existência a homens surdos E vai passando, vai dizendo

Que esta mata em redor é nossa companheira, É pedaço de nós florescendo no chão.

$[\ldots]$

Que rumor é esse na mata?

Por que se alarma a natureza?

Ai... É a moto-serra que mata,

Cortante, oxigênio e beleza.

$[\ldots]$

Samambaias, palmeiras... São alfaias

Da casa vegetal de Itatiaia.

São tesouros, bem mais que barras de ouro, 
A guardar com amor para os vindouros.

$[\ldots]$

Não, não haverá para os ecossistemas aniquilados

Dia seguinte.

O ranúnculo da esperança não brota

No dia seguinte.

O vazio da noite, o vazio de tudo

Será o dia seguinte.

As palavras do poeta, expressão literária da riqueza do bioma Mata Atlântica - uma das áreas prioritárias (botspots) para a conservação da biodiversidade (CONSERVAÇÃO INTERNACIONAL, 2005), inspiraram o Desembargador Relator a concluir:

Diante da desordenada devastação de nossas matas e da deplorável extinção de nossos bichos, intolerável coonestar iniciativas que, sob concepção exclusivamente individualista, ignoram o dever constitucional de cada um e, concomitantemente, de todos nós para com a manutenção do equilíbrio ecológico, respeitando manancial de elementos essenciais à vida humana (MINAS GERAIS, 2011).

A obra de arte, em especial a literária, pode cumprir uma função de subversão crítica em relação ao Direito, uma vez que:

[...] ela suspende nossas evidências cotidianas, coloca o dado à distância, desfaz nossas certezas, rompe com os modos de expressão convencionados. Entregando-se a toda espécie de variações imaginativas, ela cria um efeito de deslocamento que tem a virtude de descerrar o olhar. Tudo se passa como se, por ela, o real desse à luz novos possíveis que ele mantinha até então enterrados em suas profundezas. Com ela, uma forma é carregada de significação e esse surgimento é um evento único. É o gesto mesmo da poiesis: um sentido que adquire forma. [...] a obra de arte é sempre, de algum modo, uma contra-criação: um desafio ao mundo herdado, à natureza circundante, à herança cultural, e a aposta de que ainda está por ser dito algo de essencial que 
irá remodelar toda essa massa para fazer sair dela, enfim, um mundo novo [...] Compreende-se melhor, então, esta frase de Adorno: "O que seria preciso afinal inverter é a teoria da imitação. Num sentido sublimado, a realidade deve imitar as obras de arte”. (OST, 2004, p. 32-34).

Não terá sido sem razão, portanto, a assertiva de Peter Häberle, citado por Cunha $(2007$, p. 4), de que os poetas são "fornecedores de uma utopia "que orienta o sentido da realidade constitucional"'. Com o que concordará o jurista-poeta catalão Héctor López Boffill (apud CUNHA, 2007, p. 4), para quem: "Si la poesia está em el origem del orden constitucional, también podría afirmarse que la poesia es un médio de interpretación de los conceptos constitucionales".

Nos campos teórico e prático do Direito Ambiental, a Literatura contribui para demonstrar que a expressão "meio ambiente", inclusive em sua acepção jurídica, designa, para além de determinados objetos ou conjunto de objetos (sistemas naturais e seus componentes, áreas urbanas, monumentos históricos, etc.), uma relação de significado (de afetividade) ${ }^{1}$ entre eles e a coletividade. (VIEIRA, 2005; LEITE, 2003). Do mesmo modo, promove-se uma releitura da ideia, presente no texto constitucional brasileiro (art. 225, caput), da qualidade de vida, que passa a ser compreendida

[...] como passível de abarcar todos os valores culturais de uma sociedade, percebendo-se a emergência de uma nova sensibilidade em relação ao mundo natural, que se abre ao belo, à arte, ao valor da espiritualidade humana. (STEIGLEDER, 2004, p. 165)

Pela mesma razão, Leite e Ayala (2002, p. 88) afirmam:

O fato mais importante, que orienta a formação de uma posição ontológica autônoma, parece residir no reconhecimento

\footnotetext{
${ }^{1}$ A existência dessa relação serve, ao lado de outros argumentos, como justificativa teórica para o reconhecimento do dano ambiental coletivo extrapatrimonial. A propósito desse tema, ver Leite (2003) e Steigleder (2004)
} 
do valor da proteção do meio ambiente, na identificação de sua dimensão cultural. Dessa forma, justifica-se a proteção do ambiente porque ele também encerraria e simbolizaria certos valores da própria cultura.

Ao escrever o conjunto de poemas Mata Atlântica, Carlos Drummond de Andrade uniu-se às vozes que denunciaram "o sopro de destruição" (NABUCO, 1883) que tem vindo a assolar os sistemas naturais do Brasil desde o início da sua colonização. Ao mesmo tempo, o poeta exprimiu em letras seu arrebatamento ante as muitas e belas formas de vida do bioma. Oxalá esse sentimento, bem como a sensibilidade de espírito que está em sua origem, não seja um dom dos poetas apenas, mas de todos os herdeiros da Terra Brasilis, especialmente daqueles que têm a difícil missão de se pronunciar sobre o destino dos sistemas naturais do País.

\section{Referências}

ANDRADE, C. D.; MAGNANINI, A.; MARIGO, L. C. Mata Atlântica. Rio de Janeiro: AC\&M Ed., 1984.

ANDRADE, C. D. Mata Atlântica. Rio de Janeiro: AC\&M Ed.; Sette Letras, 1997.

CONSERVAÇÃO INTERNACIONAL. Hotspots revisitados: as regiões biologicamente mais ricas e ameaçadas do planeta. Disponível em: <http://www.conservation.org.br>. Acesso em: 18 jul. 2007. Original: 2005.

CUNHA, P. F. Direito e Literatura: introdução a um diálogo. Notandum, São Paulo, ano X, n. 14, 2007.

LEITE, J. R. M.; AYALA, P. A. Direito Ambiental na sociedade de risco. Rio de Janeiro: Forense Universitária, 2002.

LEITE, J. R. M. Dano ambiental: do individual ao coletivo extrapatrimonial. 2. ed., rev., atual. e ampl. São Paulo: Revista dos Tribunais, 2003. 
NABUCO, J. O abolicionismo. Disponível em: <http://www. dominiopublico.gov.br/download/texto/ bv000127.pdf $>$. Acesso em: 14 abr. 2009. Original: 1883 .

OST, F. Contar a lei: as fontes do imaginário jurídico. Tradução Paulo Neves. São Leopoldo: Unisinos, 2004.

STEIGLEDER, A. M. Responsabilidade civil ambiental: as dimensões do dano ambiental no Direito Brasileiro. Porto Alegre: Livraria do Advogado, 2004.

MINAS GERAIS. Tribunal de Justiça do Estado de Minas Gerais. Processo $\mathrm{n}^{\mathrm{o}}$ 1.0016.10.009466-9/001. Relator: Desembargador Peixoto Henriques. Acórdão: 15 fev. 2001. Disponível em: <http:// www.tjmg.jus.br>. Acesso em: 25 ago. 2011.

VIEIRA, P. F. Meio ambiente, desenvolvimento e cidadania. In: VIOLA, E. et al. (Org.). Meio ambiente, desenvolvimento e cidadania: desafios para as Ciências Sociais. São Paulo: Cortez, 2005. 